\title{
The Behavioral Consequences of Terrorism: A Meta-analysis
}

\author{
Charles DiMaggio, PhD, MPH, PA-C, Sandro Galea, MD, DrPH
}

\begin{abstract}
Effective postterrorism public health interventions require the recognition that behavioral consequences are, in fact, the intent of terrorists. The authors searched published and unpublished post-1980 studies that documented population-level behavioral and psychological consequences of terrorist incidents, focusing on posttraumatic stress disorder (PTSD). Results were tabulated, and random effects models were used to calculate overall effect sizes. The analysis indicates that in the year following terrorist incidents, the prevalence of PTSD in directly affected populations varies between $12 \%$ and $16 \%$. The review also shows that this prevalence can be expected to decline $25 \%$ over the course of that year. These prevalence estimates mask great variability, depending on who is being studied, who is conducting the study, and where the event occurred. Higher rates of disease are reported for survivors and rescue workers, and higher overall rates are also reported from studies conducted in Western Europe compared with studies conducted in North America. Prior psychiatric diagnoses are strongly associated with subsequent PTSD and may be a useful triage factor, particularly when considered together with factors such as female gender and direct exposure to events as either a survivor or rescuer. The review indicates that these associations are consistent across study types and environments and represent important variables to consider when developing triage, outreach, and treatment programs.
\end{abstract}

ACADEMIC EMERGENCY MEDICINE 2006; 13:559-566 @ 2006 by the Society for Academic Emergency Medicine

Keywords: behavioral health, posttraumatic stress disorder, meta-analysis

$\mathrm{T}$ errorism is an ongoing concern throughout the world. The U.S. Department of State documented 228 acts of worldwide terrorism between 1961 and 2003. ${ }^{1}$ Of these, 197 were in the developing world. In the United States, attention has turned to the threat of terrorism with the September 11, 2001, terrorist bombings, ${ }^{2-4}$ the largest single-day loss of human life in U.S. history since the Civil War. Subsequent terrorist attacks, such as the October 12, 2002, Bali nightclub bombings, the March 11, 2004, Madrid train bombings, and the July 7, 2005, London bombings, have further brought the threat of terrorism to the forefront of national and international discourse.

Several large-scale reviews of the consequences of disasters have been published. ${ }^{5-7}$ These reviews have

From the Mailman School of Public Health, Columbia University (CJD), New York, NY; and School of Public Health, University of Michigan (SG), Ann Arbor, MI.

Received October 6, 2005; revision received November 9, 2005; accepted November 11, 2005.

Address for correspondence and reprints: Charles DiMaggio, PhD, MPH, PA-C, Mailman School of Public Health, Columbia University, 722 West 168 Street, Room R806, New York, NY 10032. Fax: 212-342-5163; e-mail: cjd11@columbia.edu. documented the prevalence and correlates of specific psychiatric disorders and behaviors after mass events. Posttraumatic stress disorder (PTSD) emerges from this work as the best studied, and likely most common, psychopathology after disasters. One theme to arise from these reviews is that disasters that are caused by human intent (such as terrorism) may be associated with a particularly high risk of psychopathology in their aftermath. ${ }^{7}$ As such, explicit study of the mental health consequences of terrorism may be warranted. To illuminate this issue, we undertook a review and synthesis of quantitative studies of the behavioral health effects of terrorist incidents, focusing primarily on the prevalence and correlates of PTSD.

\section{METHODS}

We searched published and unpublished post-1980 studies of empirical data utilizing survey methodology and presenting quantitative population-level results of behavioral health effects of terrorist incidents. Reports presenting secondary analyses of previously published data such as meta-analyses, studies of qualitative data such as focus groups, editorials, review articles, commentaries, and case reports were excluded. 


\section{Eligibility Criteria}

For the purposes of this review, terrorism was defined as "the intentional use of violence-real or threatenedagainst one or more non-combatants and/or those services essential for or protective of their health, resulting in adverse health effects in those immediately affected and their community, ranging from a loss of well-being or security to injury, illness, or death." ${ }^{8}$ We limited our search to studies that were closely defined by time and place and excluded studies of torture and long-term political repression as well as studies of the effects of expatriation on political refugees. We also excluded incidents of random, nonpolitically motivated violence such as criminal shootings by potentially psychotic individuals. Behavioral health effects were defined as PTSD, depression, substance abuse, and potentially related somatic signs and symptoms, such as asthma and cardiovascular disease. These last two somatic disorders were chosen based on their presence in the literature as an area of behavioral research. Studies of PTSD were limited to those with diagnostic criteria referenced to a current diagnostic and statistical manual (DSM-IV). ${ }^{9}$

Studies were eligible for analysis if they presented results in terms of proportions or prevalences, odds ratios of dichotomous variables, means with standard deviations, p-values, t-tests, F statistics, and chi squares, or with data that could be translated into one of those terms. Where possible, univariate data were extracted from studies with results of multivariate analyses.

\section{Search and Coding}

We electronically searched PubMed, MEDLINE, Cumulative Index of Nursing and Allied Health Literature (CINAHL), Allied and Complementary Medicine (AMED), PsychINFO, Health and Psychosocial Instruments, ProQuest Digital Dissertation Database, Papers First (a compendium of conference proceedings from the British Library), Cochrane Reviews, ACP Journal Club, Database of Abstracts of Reviews of Effectiveness (DARE), the Cochrane Controlled Trials Register (CCTR), Sociologic Abstracts, and Web of Science by entering the terms "terror*," "posttraumatic stress," "health" and "effects" "behavior*," "disaster" and "psychiatr*," and "mass violence" singly and in combination ${ }^{*}$ refers to wildcard characters).

Articles were entered into Endnote 9.0. ${ }^{5}$ To identify quantitative epidemiologic studies, titles and abstract text were electronically searched for the following terms: study, investigation, incidence, prevalence, proportion, effect, random*, population, research, cross-sectional, ecologic, and epidem*. References to night terrors and sleep disturbances were excluded by visual inspection of the report. Primarily bioterrorism-related articles were identified by searching for and visually inspecting references to smallpox, anthrax, plague, and radiologic and were omitted if they did not include a primary behavioral component. The remaining titles and abstracts of these references were visually searched to remove duplicates, reports primarily addressing physical injury, and reports addressing natural disasters.

Full-text versions of articles entered into the study were reviewed by the primary author and coded for the following variables: mean age, race and gender distribu- tion, geographic area, mechanism of injury, specific event or incident, time elapsed between incident and study, type of subjects, primary outcome of interest, method of recruitment and enrollment, participation rate, type of assessment, scale or instrument used and whether validation measures were presented, and version of diagnostic and statistical manual used.

\section{Data Analysis}

We first identified and described all eligible reports addressing the behavioral consequences of terrorism. We then focused on the subset of reports presenting results primarily concerned with PTSD. For these reports, results were tabulated and effect size calculated. Using a random effects model, results were analyzed for 1) central tendency or overall mean effect size, as well as its variance and its statistical significance as estimated by $95 \%$ confidence intervals (CIs); 2) heterogeneity of the mean effect size as assessed and tested through chi-square distribution of Q statistic; and 3) evaluation of the relationship of effect size to moderator variables such as geographic location, type of incident, magnitude of the incident measured in number injured, and impact level on individuals surveyed.

Summary statistics and Forrest plots were created using Comprehensive Meta Analysis version 2 (Biostat Inc., Englewood, NJ). Descriptive statistics were conducted using SAS System for Windows version 9.0 (SAS Institute, Inc., Cary, NC) and SPSS version 11.5 (SPSS Inc., Chicago, IL).

\section{RESULTS}

\section{Behavioral Studies}

A total of 4,977 references were retrieved through the electronic database search. A total of 1,411 remained after removing duplicates, commentaries, case reports, general review articles, essays, references to night terrors and sleep disturbances, and bioterrorism-related reports if they did not include a primary behavioral component. A total of 250 reports remained after removing additional duplicates, reports primarily addressing physical injury, and reports primarily addressing natural disasters. Hand searching the references of articles eligible for inclusion identified an additional five references. Of these 255 studies, 142 were excluded for the following reasons: commentary (27), subjective data (13), nonindependent or previously presented data (13), not behavioral health, as defined for study (22), review article or textbook chapter (23), not terrorism, as defined for study (20), not English (5), insufficient information to code (8), and unable to locate or retrieve (11). References of excluded articles were not hand searched. A total of 113 reports addressing behavioral health outcomes remained. (These are listed in the Appendix, available as a Data Supplement at http://www.aemj.org/cgi/content/full/j.aem. 2005.11.083/DC1.)

The majority of initially eligible studies (99/113) were based on inner-city or urban populations. Fifty-one of the 113 selected reports addressed populations that were more than $60 \%$ white. Ten studies included populations that were more than $40 \%$ African American. One study included a population that was more than $40 \%$ 


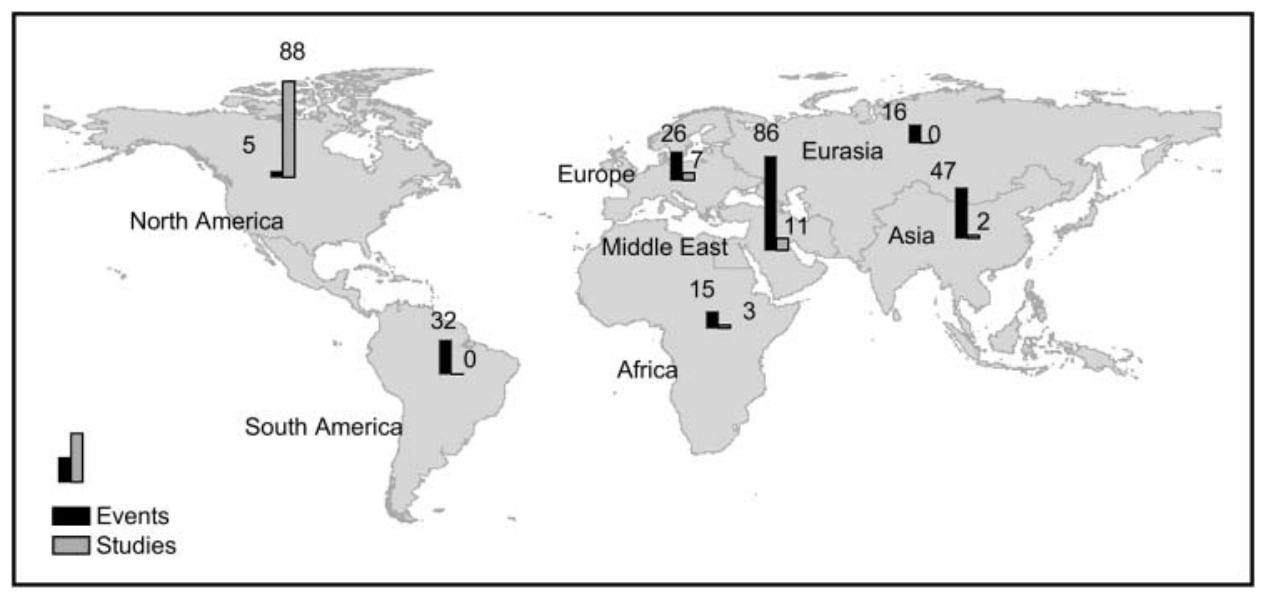

Figure 1. Proportion of postterrorism behavioral health studies entered into analysis (gray) compared with proportion of reported terrorist incidents since 1980 (black) by region of the world.

Hispanic. Twelve studies $(10.6 \%)$ explicitly studied children. Sixty reports $(53 \%)$ studied predominantly female populations.

Only two of the initial 113 eligible behavioral health studies involved biologic incidents; the remaining studies addressing explosions or armed attacks. Sixty percent $(68 / 113)$ of the studies addressed an incident in which more than 2,000 persons were killed. Twenty percent (22/113) involved an incident in which 100-250 persons were killed. Forty-four reports $(38.9 \%)$ studied a general population sample, 16 reports $(14.2 \%)$ studied survivors, five reports $(4.4 \%)$ studied rescuers, and 11 reports $(9.7 \%)$ studied employment groups. Figure 1 represents the proportion of the 113 studies initially eligible for inclusion in the analysis by region of the world compared with the proportion of all reported terrorist incidents in the region during the same period. ${ }^{1}$

Table 1 presents the behavioral health outcomes of the 113 behavioral health reports. Of these 113 studies initially eligible for inclusion, 61 (54\%) addressed PTSD and were entered into subsequent analysis.

\section{PTSD}

Forty-six of the 61 PTSD studies listed explicit DSMbased diagnostic criteria; the most commonly cited version (30/46) was DSM-III-R. ${ }^{10}$ Thirty-seven of the 61 studies $(61 \%)$ used validated screening instruments. The most frequently used screening instrument $(16 / 37$ $[43.2 \%]$ ) was the Impact of Event Scale. ${ }^{11}$

The 61 PTSD reports included 146 outcome effects. Forty-two $(28.8 \%)$ of the effects were prevalence measures; $80(54.8 \%)$ were measures of association. Seventy-nine $(54.1 \%)$ of the effect sizes were either an increased prevalence compared with unaffected population estimates or a positive association with the covariate under investigation. The majority $(78.8 \%)$ of effects were measured within six months of the terrorist incident.

We calculated an overall, global measure of the prevalence of PTSD after terrorist attacks that included all studies of victims, rescuers, occupational groups, and general population samples. Postterrorism prevalence of PTSD varied by time. For studies conducted up to two months after the event, the overall prevalence rate was approximately $16 \%$. At six months, the prevalence was approximately 14\%; at one year, the prevalence was $12 \%$. These declines were statistically significant (p < 0.0001) (Figure 2).

For the 14 studies with populations that were more than $60 \%$ white, the global average postterrorism prevalence of PTSD was $18.4 \%$ (95\% CI $=14.8 \%$ to $22.6 \%$ ). Two studies had a greater than $40 \%$ African American composition with an average prevalence of $14.8 \%$ (95\% CI $=$ $1.7 \%$ to $63.1 \%$ ). One study addressed a greater than $40 \%$ Hispanic population and reported a prevalence of $13.6 \%(95 \% \mathrm{CI}=8.4 \%$ to $21.4 \%)$.

For studies with predominantly male populations $(>80 \%)$, the global average prevalence of PTSD was $11.3 \%(95 \%$ CI $=6.0 \%$ to $20.4 \%)$. For predominantly female populations, the overall prevalence was $16.2 \%$ $(95 \%$ CI $=11.8 \%$ to $21.8 \%)$. There was a slight decline in PTSD associated with increasing mean age in study samples (slope $=-0.00763 ; \mathrm{p}<0.0001$ ).

Overall, studies conducted in Western Europe reported a higher prevalence $(23.6 \% ; 95 \% \mathrm{CI}=19.6 \%$ to $28.1 \%$ ) when compared with studies conducted in North America $(12.7 \%$; $95 \%$ CI $=9.1 \%$ to $17.5 \%$ ) or the Middle East $(12.6 \% ; 95 \% \mathrm{CI}=8.8 \%$ to $17.9 \%)$. There were also variations within the same geographic area. Studies of the Oklahoma City bombing reported a global PTSD

\begin{tabular}{|c|c|c|}
\hline \multicolumn{3}{|c|}{$\begin{array}{l}\text { Table } 1 \\
\text { Primary Outcomes of Studies Included in Systematic Review of } \\
\text { Postterrorism Behavioral Health Disturbances }\end{array}$} \\
\hline & Frequency & Percent \\
\hline Posttraumatic stress disorder & 61 & 54.0 \\
\hline Depression & 10 & 8.8 \\
\hline Stress/anxiety & 5 & 4.4 \\
\hline Substance abuse & 7 & 6.2 \\
\hline Other primarily behavioral outcome & 18 & 15.9 \\
\hline Respiratory symptoms & 2 & 1.8 \\
\hline Cardiac symptoms & 1 & 0.9 \\
\hline Other somatic disorder & 8 & 7.1 \\
\hline Unable to determine & 1 & 0.9 \\
\hline Total & 113 & 100.0 \\
\hline
\end{tabular}




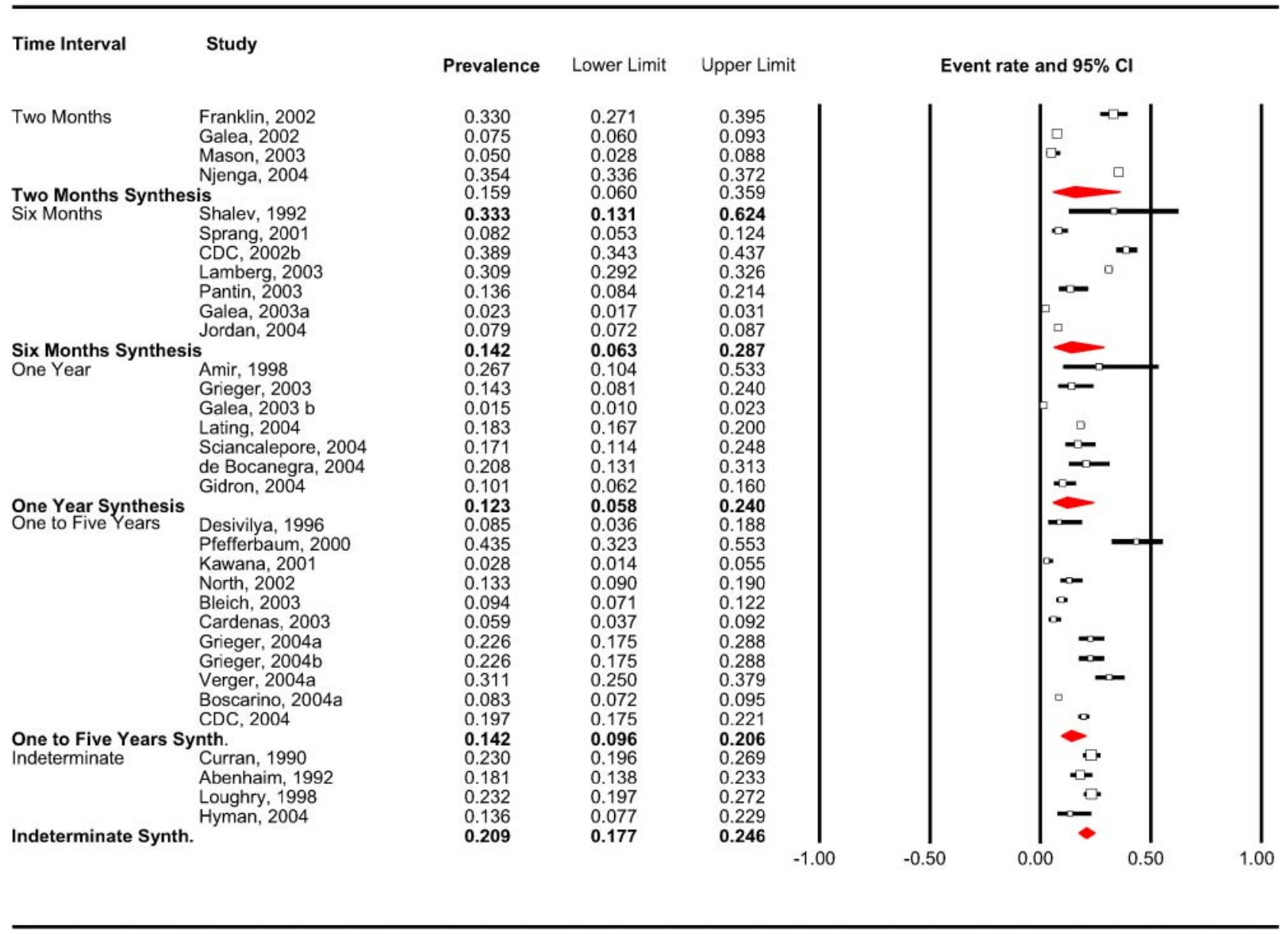

Figure 2. Prevalence of posttraumatic stress disorder by time from event. Systematic review of postterrorism behavioral health disturbances.

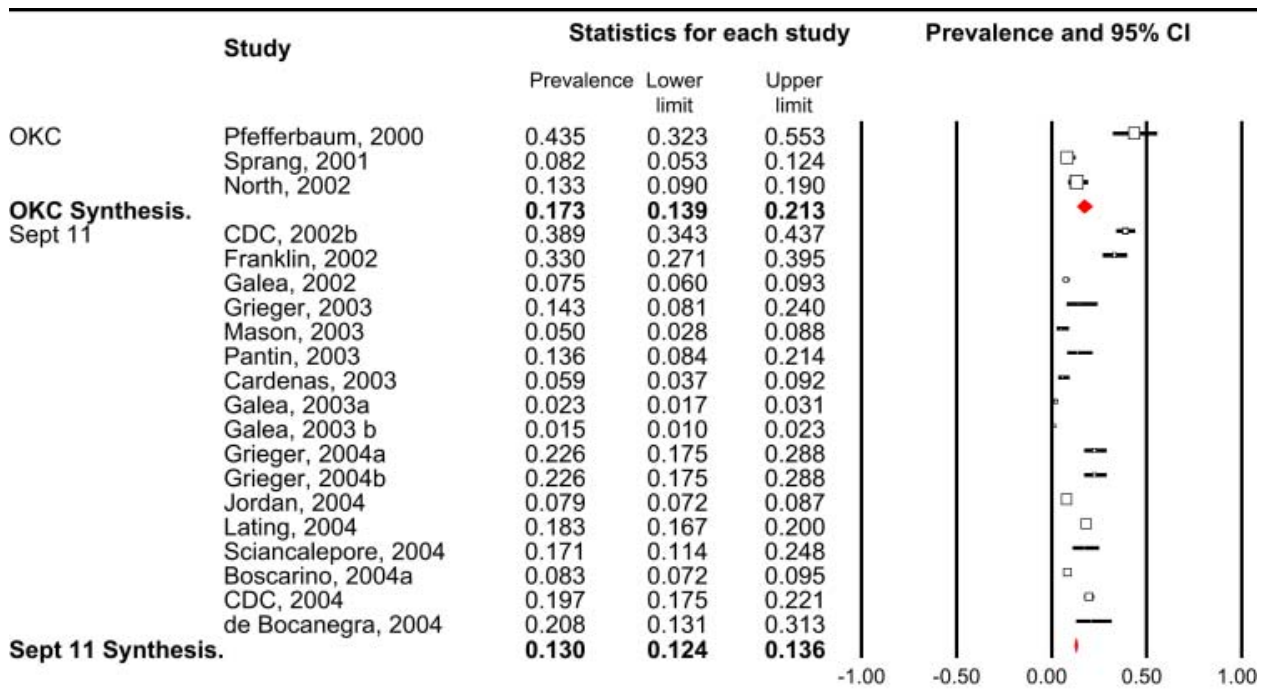

Figure 3. Terrorism-related posttraumatic stress disorder prevalence effect sizes grouped by event within the United States. OKC = Oklahoma City bombing; Sept $11=$ World Trade Center attacks. 


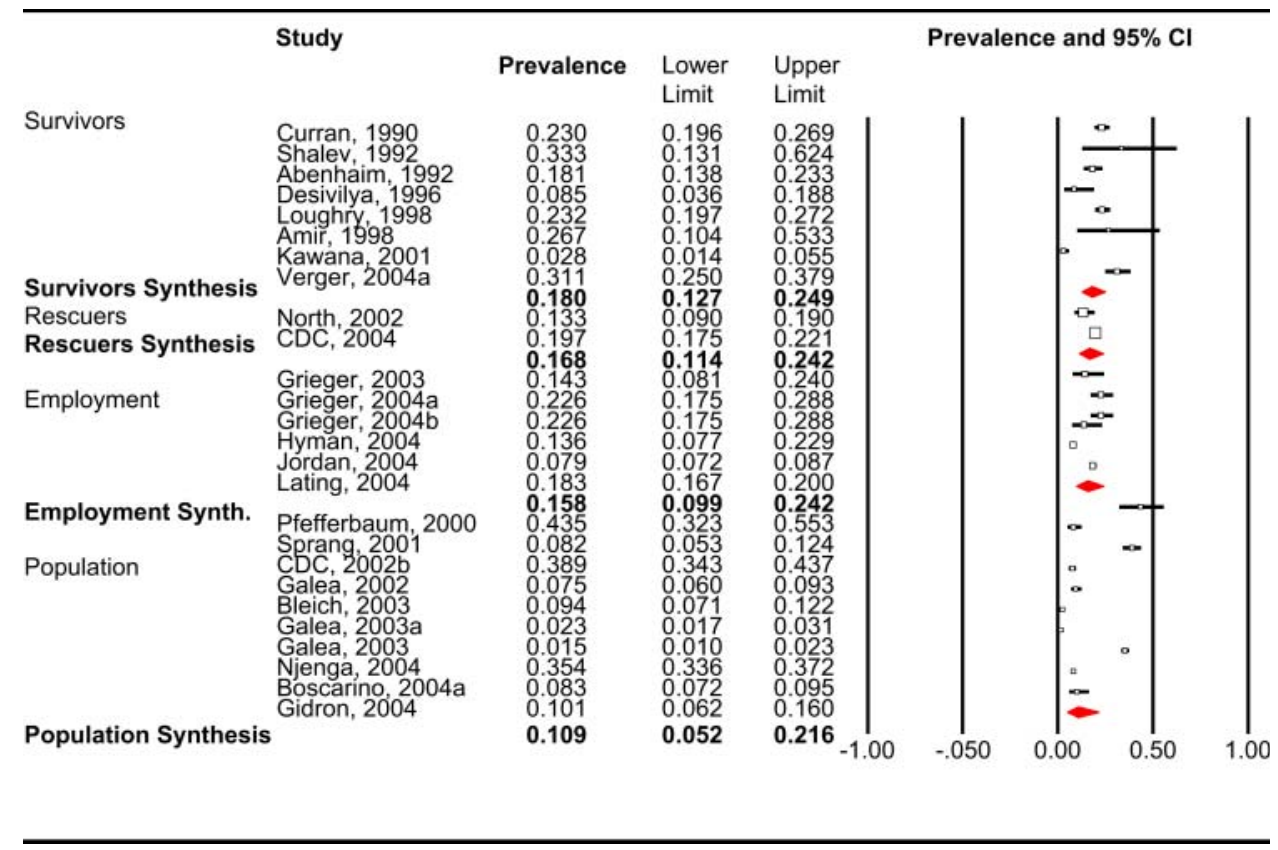

Figure 4. Terrorism-related posttraumatic stress disorder prevalence effect sizes grouped by exposure category (survivors, rescuers, employees, general population).

prevalence of $17.35 \%$ (95\% CI $=12.9 \%$ to $21.3 \%)$. Studies of the New York City September 11, 2001, attacks reported a global prevalence of $13.0 \%$ (95\% CI $=12.4 \%$ to $13.6 \%$ ) (Figure 3 ).

Studies of survivors reported an average PTSD prevalence of $18 \%$ ( $95 \% \mathrm{CI}=12.7 \%$ to $24.9 \%$ ). Rescuers had an average prevalence of $16.8 \%$ (95\% CI $=11.4 \%$ to $24.2 \%$ ), and exposed employment cohorts had an average prevalence of $15.8 \%$ (95\% CI $=9.9 \%$ to $24.2 \%)$. Surveys conducted on general population samples that did not explicitly target survivors, rescuers, or occupational groups reported an average prevalence of $10.9 \%(95 \%$ $\mathrm{CI}=5.2 \%$ to $21.6 \%$ ) (Figure 4 ). We divided these general population surveys into those geographically situated within 100 miles of the events (local populations) and those farther than 100 miles of the events (distant populations). There was little difference between studies that surveyed local populations (prevalence, 7.9\%; 95\%
$\mathrm{CI}=3.3 \%$ to $17.6 \%$ ) versus those that surveyed distant populations (prevalence, $9.5 \% ; 95 \% \mathrm{CI}=7.5 \%$ to $12 \%$ ) (Figure 5).

Nine studies examined the association between viewing media images of terrorist events and subsequent assessments of PTSD. Overall, individuals who viewed media images of events were twice as likely to be assessed as having PTSD (odds ratio for association = 1.9; $95 \%$ CI $=1.5$ to 2.5 ). This effect was time dependent, with the five studies conducted within three months of the events indicating an odds ratio for association of $2.4(95 \% \mathrm{CI}=2.1$ to 2.8$)$ and the three studies conducted between three and six months after the events indicating an overall odds ratio for association of $1.3(95 \% \mathrm{CI}=1.1$ to 1.6$)$.

Four studies examined the association between prior psychiatric history and subsequent assessments of PTSD, and the summary odds ratio for association was

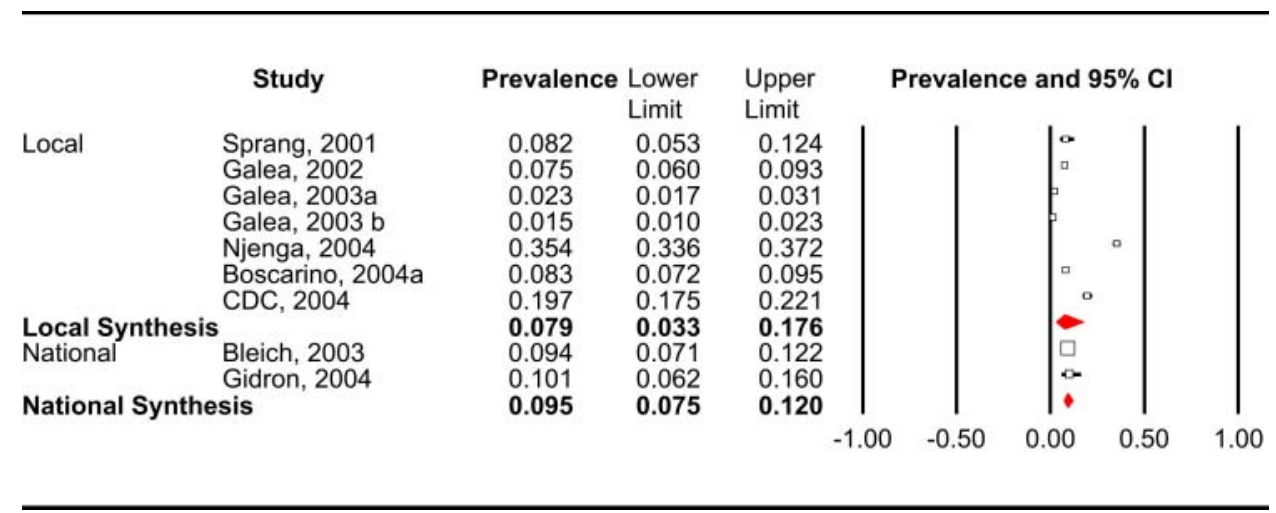

Figure 5. Terrorism-related posttraumatic stress disorder prevalence effect sizes grouped by general population categories. Local $=<20$ miles; national $=>100$ miles. 
$4.0(95 \%$ CI $=2.1$ to 7.4$)$. Eight studies examined the association between female gender and subsequent assessments of PTSD, and the summary odds ratio for association was $2.2(95 \% \mathrm{CI}=1.4$ to 3.3$)$.

\section{DISCUSSION}

The behavioral consequences of terrorist incidents have received considerable recent academic attention, much of it driven by the Oklahoma City bombings and the attacks of September 11, 2001, in the United States. There are both immediate and long-term implications for the emergency medicine community. ${ }^{12}$ These include familiarity with the ways in which patients may present to emergency departments following disasters and terrorist incidents, the need to identify populations and groups most at risk of developing long-term behavioral sequelae such as PTSD, and an appreciation of the impact such events may have on the overall health status of emergency department patients.

The reported prevalence of all types of psychopathology following disasters varies from $7 \%$ to $70 \% .{ }^{13}$ Our analysis indicates that in the year following terrorist incidents, the prevalence of PTSD in directly affected populations varies between $12 \%$ and $16 \%$. Our review also shows that this prevalence can be expected to decline $25 \%$ over the course of that year. We could not assess how interventions affect this decline.

These prevalence estimates mask great variability depending on who is being studied, who is conducting the study, and where the event occurred. The populations studied tended to be white, adult, male North Americans, and the incidents were most likely to be explosions and violent attacks. PTSD continues to attract the most attention from researchers. The choice of PTSD as an area of interest for researchers also likely reflects the availability of validated screening tools amenable to research settings, the increasing consensus that PTSD is a likely outcome of postterrorism environments, and the sense that PTSD is a marker or covariate for other behavioral disturbances. Overall, studies show that survivors of terrorist incidents consistently have the highest rates of PTSD. Rescuers and first responders were at next highest risk. Although other outcomes such as depression and substance abuse have garnered increasing attention, studies of noninjury somatic disturbances received relatively little attention and may be an area for future research.

While we limited our analysis to studies presenting outcomes based on validated diagnostic and screening instruments, changes in diagnostic criteria for PTSD over time $\mathrm{g}^{9,10,14}$ and the myriad available screening instruments available for assessing PTSD ${ }^{11,15-18}$ make comparisons difficult even within the same geographic region. These different diagnostic and screening standards demand cautious interpretation of literature syntheses.

The higher prevalence reported in Western Europe lends credence to the idea that there are also local, cultural aspects to the diagnosis of PTSD that preclude easy comparisons. It is unfortunate that there were insufficient studies to include regions such as Asia, South America, and the Indian Subcontinent, but there was sufficient variation among the regions that were represented to demonstrate the importance of taking geographic variation into account as well.

Several studies have addressed the effect of disasters on children. The risk for developing postdisaster PTSD varies by age, with an increase during school age, followed by a second more prominent increase during middle age. ${ }^{6}$ Most such studies present symptoms rather than diagnoses. Although we did not explicitly exclude children, by requiring diagnostic assessments for a study to be included, there were no studies of children that met inclusion criteria for our analysis. It should be noted, for example, that although our regression of age on the logit of event rate indicates an age effect, the data do not include pediatric populations. There is a need for further study addressing this important group.

The $40 \%$ higher prevalence of postterrorism PTSD among predominantly female populations that we found mirrors the general disaster literature. Ninety-four percent of studies that looked at gender found that being female was associated with an increased risk of postdisaster behavioral health disturbance, ${ }^{7}$ with women reported as being twice as likely to develop PTSD. ${ }^{19} \mathrm{Mar}-$ riage and parenthood are also associated with increased risk. ${ }^{6}$ Taken together, these associations point to the potential common mediating factor of an imbalance of resources, or the stress of caring for others and being obligated to provide more resources than are received. ${ }^{7}$ The only postdisaster behavioral outcome associated with men is alcohol abuse. ${ }^{7}$

Although there was a suggestion of variation by race, our results were statistically inconclusive. Minority status and lower socioeconomic status are generally associated with increased risk of postdisaster behavioral diagnoses. This is at least in part due to increased risk of exposure. ${ }^{6}$

We found an association between media exposure and PTSD, but many of the studies were cross-sectional. Causality might equally plausibly flow from the exposure of viewing media images to PTSD or from individuals with PTSD being drawn to media images of the event. That the association of viewing media images with PTSD declined with time in a fashion similar to overall PTSD prevalence supports both the notion that the presence of PTSD in an individual drives media viewing and perhaps the expected decline in media coverage with time.

We did not demonstrate a substantial difference in prevalence of PTSD among samples drawn from populations close to events (but excluding survivors and rescuers) compared with those drawn from populations farther removed from the event. This is in part due to the relatively few studies available for comparison and perhaps also the role of the media in dispersing images of events, particularly in Western nations. It also reflects the contradictory evidence on the effects of terrorist events on the general population. In the immediate postattack period, there were reports of anxiety-related diagnoses of nearly 50\% in New York City's Chinatown (located in the immediate vicinity of the World Trade Center). ${ }^{20}$ Another study reported that symptoms of emotional distress were evident even at long distances from the East Coast, with $91 \%$ of respondents to a national survey having at least one stress-related symptom and $44 \%$ having one or more substantial symptoms. ${ }^{21}$ In contrast, there was no increased demand for mental 
health services in Canada following September 11, 2001.22 In the midwestern United States, $5.9 \%$ of respondents to a survey had evidence of PTSD, exactly matching the prevalence of national surveys preceding the events of September 11, 2001. ${ }^{23}$ However, this might be due to our inability to categorize geographic distances more precisely.

\section{LIMITATIONS}

This study was subject to a number of potential limitations, some of which have already been mentioned. Meta-analyses should be interpreted cautiously. An overreliance on summary statistics may obscure theory. Studies may be so heterogeneous as to challenge the basis of combining them, and there may be undetected systematic variation among studies. A meta-analysis can only be as valid and reliable as the studies on which it is based. ${ }^{24}$ Part of our analysis, for example, pooled studies of survivors, rescue personnel, and local populations. These are three disparate groups likely to have different responses to terrorist incidents.

Despite these difficulties, synthetic analysis has the advantages of providing a disciplined, theoretically sound, and systematic approach that avoids some of the subjective and indiscriminant aspects of traditional literature reviews. We took efforts to apply the most valid aspects of meta-analytic technique and avoid potential pitfalls. A priori variable definitions and study criteria were posited. The search process was explicitly described and documented. Studies were coded so as to enhance the ability to combine them in valid ways. A random effects statistical approach was adopted for all analyses in recognition of the likely heterogeneity of included studies. In addition, we attempted to balance the quantitative aspects of the review with the qualitative.

This review has implications for treatment and public health control. Prior psychiatric diagnoses are strongly associated with subsequent PTSD and may be a useful triage factor, particularly when taken with factors such as female gender and direct exposure to events as either a survivor or rescuer. Our review indicates that these associations are consistent across study types and environments and represent important variables to consider when developing triage, outreach, and treatment programs.

\section{CONCLUSIONS}

Terrorism is psychological warfare, ${ }^{25}$ and behavioral disturbance is the primary intent of terrorists. Effective postterrorism public health interventions require the recognition that behavioral consequences are, in fact, the intent of terrorists. Although most people in the general population can be expected to recover spontaneously within several months to one year, emergency department practitioners can contribute to interventions to facilitate and speed the process. These include recognition of honest appraisals of behavioral health effects in community health announcements, preserving as much as possible community, family, and social networks, and returning individuals to normal activities as soon as feasible. Finally, some individuals such as survivors, rescuers, and those with a prior psychiatric history are at increased risk of conditions such as PTSD and may require outreach efforts and individual interventions.

\section{References}

1. Significant Terrorist Incidents, 1961-2003: A Brief Chronology. Available at: http://www.state.gov/r/pa/ ho/pubs/fs/5902.htm. Accessed Aug 16, 2005.

2. Laraque D, Boscarino JA, Battista A, et al. Reactions and needs of tristate-area pediatricians after the events of September 11th: implications for children's mental health services. Pediatrics. 2004; 113 1357-66.

3. Boscarino JA, Galea S, Ahern J, Resnick H, Vlahov D. Utilization of mental health services following the September 11th terrorist attacks in Manhattan, New York City. Int J Emerg Ment Health. 2002; 4:143-55.

4. Vlahov D, Galea S, Ahern J, Resnick H, Kilpatrick D. Sustained increased consumption of cigarettes, alcohol, and marijuana among Manhattan residents after September 11, 2001. Am J Public Health. 2004; 94: 253-4.

5. Galea S, Nandi A, Vlahov D. The epidemiology of post-traumatic stress disorder after disasters. Epidemiol Rev. 2005; 27:78-91.

6. Norris FH, Friedman MJ, Watson PJ, Byrne CM, Diaz E, Kaniasty K. 60,000 disaster victims speak: part I. An empirical review of the empirical literature, 1981-2001. Psychiatry. 2002; 65:207-39.

7. Norris FH, Friedman MJ, Watson PJ. 60,000 disaster victims speak: part II. Summary and implications of the disaster mental health research. Psychiatry. 2002; 65:240-60.

8. Arnold JL, Ortenwall P, Birnbaum ML, et al. A proposed universal medical and public health definition of terrorism. Prehosp Disaster Med. 2003; 18:47-52.

9. American Psychiatric Association. Task Force on DSM-IV. Diagnostic and Statistical Manual of Mental Disorders: DSM-IV. ed 4. Washington, DC: American Psychiatric Association, 1994.

10. American Psychiatric Association. Diagnostic and Statistical Manual of Mental Disorders: DSM-III-R. ed 3. Washington, DC: American Psychiatric Association, 1987.

11. Horowitz M, Wilner N, Alvarez W. Impact of Event Scale: a measure of subjective stress. Psychosom Med. 1979; 41:209-18.

12. Fernandez WG, Galea S, Miller J, et al. Health status among emergency department patients approximately one year after consecutive disasters in New York City. Acad Emerg Med. 2005; 12:958-64.

13. Lovejoy DW, Diefenbach GJ, Licht DJ, Tolin DF. Tracking levels of psychiatric distress associated with the terrorist events of September 11, 2001: a review of the literature. J Insur Med. 2003; 35: 114-24.

14. American Psychiatric Association. Desk Reference to the Diagnostic Criteria from DSM-III. Washington, DC: American Psychiatric Association, 1982.

15. Blake DD, Weathers FW, Nagy LM, et al. The development of a clinician-administered PTSD Scale. J Trauma Stress. 1995; 8:75-90. 
16. Lindal E, Stefansson JG. The lifetime prevalence of anxiety disorders in Iceland as estimated by the US National Institute of Mental Health Diagnostic Interview Schedule. Acta Psychiatr Scand. 1993; 88:29-34.

17. Blanchard EB, Jones-Alexander J, Buckley TC, Forneris CA. Psychometric properties of the PTSD Checklist (PCL). Behav Res Ther. 1996; 34: 669-73.

18. Breslau N, Davis GC, Peterson EL, Schultz L. Psychiatric sequelae of posttraumatic stress disorder in women. Arch Gen Psychiatry. 1997; 54:81-7.

19. North CS. Psychiatric effects of disasters and terrorism: empirical basis from study of the Oklahoma City bombing. Paper presented at: American Psychopathological Association meeting "Fear and Anxiety: The Benefits of Translational Research, " Mar 2002.

20. Chen H, Chung H, Chen T, Fang L, Chen JP. The emotional distress in a community after the terrorist attack on the World Trade Center. Community Ment Health J. 2003; 39:157-65.

21. Schuster MA, Stein BD, Jaycox L, et al. A national survey of stress reactions after the September 11, 2001, terrorist attacks. N Engl J Med. 2001; 345:1507-12.

22. Austin PC, Mamdani MM, Chan BT, Lin E. Anxietyrelated visits to Ontario physicians following September 11, 2001. Can J Psychiatry. 2003; 48:416-9.

23. Cardenas J, Williams K, Wilson JP, Fanouraki G, Singh A. PSTD, major depressive symptoms, and substance abuse following September 11, 2001, in a midwestern university population. Int $\mathrm{J}$ Emerg Ment Health. 2003; 5:15-28.

24. Lipsey MW, Wilson DB. Practical meta-analysis. Thousand Oaks, Calif: Sage Publications, 2001.

25. Alexander D. Psychological aspects of terrorism. Paper presented at: 14th World Congress on Disaster and Emergency Medicine, Edinburgh, Scotland, May 2005. 